\title{
Environmental Method to Determine Dopamine and Ascorbic Acid Simultaneously via Derivative Spectrophotometry
}

\author{
Ahmed M. El-Zohry and E. Y. Hashem \\ Chemistry Department, Faculty of Science, Assiut University, Assiut 71516, Egypt \\ Correspondence should be addressed to Ahmed M. El-Zohry; amfzohry@yahoo.com
}

Received 11 May 2013; Accepted 7 October 2013

Academic Editor: M. Carmen Yebra-Biurrun

Copyright ( 2013 A. M. El-Zohry and E. Y. Hashem. This is an open access article distributed under the Creative Commons Attribution License, which permits unrestricted use, distribution, and reproduction in any medium, provided the original work is properly cited.

\begin{abstract}
Many various methods were applied to determine dopamine and ascorbic acid simultaneously using hazardous materials and complex procedures. Derivative absorption spectra can give safely and five sensitive derivative equations that are used for the simultaneous determination of dopamine and ascorbic acid in the UV region, using first and second derivative spectroscopy with high precision at $\mathrm{pH}$ value of 9.2. Dopamine and ascorbic acid can be detected in the ranges of $0.375-9.45 \mathrm{mg} \mathrm{L}^{-1}$ and $0.352-5.28 \mathrm{mg}$ $\mathrm{L}^{-1}$, respectively. These obtained methods could be used to determine both reagents in real and synthesized samples.
\end{abstract}

\section{Introduction}

Dopamine (DA) is a neurotransmitter, which plays a key role in research on the pathology of Parkinson's disease (PD) [1]. The development of dopamine determination methods has attracted scientists' attention for years and extensive work has been carried out on it. For the proper treatment of PD patients, biomedical analysis requires reliable and efficient tools for analytical implementations. Many researchable groups focused on the problems of recognition and selective determination of catechol amines, especially dopamine, with optical detection methods. As physiological level of dopamine is as low as $0.2-0.30 \mu \mathrm{mol} \mathrm{L} \mathrm{L}^{-1}$, analytical methods should be very sensitive whereas in pharmaceutical preparations dopamine concentration is in several orders of magnitude higher (ca. $40 \mathrm{~g} \mathrm{~L}^{-1}$ ), so less sensitive spectrophotometric methods could be applied.

For the dopamine injections, the United States Pharmacopoeia (USP) recommends high-performance liquid chromatographic separation followed by spectrophotometric detection at $280 \mathrm{~nm}$ [2]. This procedure requires a specific column for analytical separation and sample pretreatment procedures, such as degassing and filtration, leading to a tedious procedure for routine analyses. Other analytical techniques for dopamine determination in pharmaceutical preparations referred to in the literature also require time consuming and tedious pretreatment of samples, the most frequent being spectral methods such as ultraviolet-visible absorption [3-14], fluorescence [15-21], and chemiluminescence [22]. Electroanalytical methods, namely, voltammetry [23-26], amperometry [27], and polarography [28, 29], were also described in the literature. Recently, great efforts were done in this direction with a lot of long, expensive, and sophisticated procedures using, for example, monolayer of triazole on gold electrodes [30], using gold nanoparticles [31-33], using modified glassy carbon electrode [34, 35], using silver nanoparticles [36], and using even a highly toxic substances such as mercury [16]. Similarly, ascorbic acid (AA) is a vital vitamin in the diet of human. AA has been used for the prevention and treatment of common cold and mental illness, infertility, cancer, and AIDS. In mammalian tissue, AA is present along with several neurotransmitters including DA, while, in biological samples, DA often occurs with AA in relatively high concentrations [37].

AA is oxidized at similar potential of DA at conventional electrode and has much larger signals in the brain than DA [38]. As DA and AA are electroactive substances, electrochemical methods are of the most favourable techniques for the determination of both compounds $[39,40]$. However, one of the major problems encountered in the electrochemical 
determination of DA is the intervention of $\mathrm{AA}$, which has similar structure and oxidation potential close to those of DA at most solid electrodes, resulting in a great difficulty of their simultaneous determination due to overlapped signals. Moreover, the bare solid electrodes often suffer from the fouling effect due to the accumulation of oxidized products on the electrode surface, leading to the rather poor selectivity and sensitivity [40].

Derivative spectrophotometry is an analytical technique of great utility for extracting both qualitative and quantitative information from spectra composed of unresolved bands [41-43]. The derivative method has found applications not only on the ultraviolet-visible region spectrophotometry, but also in infrared, atomic absorption, flame emission spectrophotometry, and also in fluorimetry [44-47]. Derivative spectrophotometry has been shown to be more versatile than classical spectrophotometry for solving analytical problems. It leads not only to an increase in selectivity, but also, in many cases, to an increase in sensitivity [48-50]. The scale of this increase depends on the shape of the normal absorption spectra of the analyte and the interfering substances, as well as on instrumental parameters technique (e.g., peak-to-trough on zero crossing) chosen by the analyst in a given analytical procedure [51-53].

For a single peak spectrum, the first derivative is a plot of the gradient $d A / d \lambda$ of the absorption envelope versus wavelength and features a maximum and a minimum, the vertical distance between these is the amplitude, which is proportional to the analyte concentration theoretically, and $d A / d \lambda$ is zero at $\lambda_{\max }$ for the band in the normal spectrum. The second derivative spectrum, $d^{2} A / d \lambda^{2}$ versus $\lambda$, has two maximum with a minimum between them at the $\lambda_{\text {max }}$ location in the normal absorption band. In this work, we could overcome all of the above shown disadvantages by using first and second derivative equations, which are not reported before in the literature survey to detect both of DA and AA by ultraviolet-visible absorption technique, as it is considered one of the most cheapest techniques with high sensitivity and easiest operation. Also, with this method, we have not used expensive chemicals or columns, or hazardous solvents which could be harmful to the environment. The obtained data are highly precise with highly speed acquisition.

\section{Experimental}

2.1. Instruments. Absorption measurements were made on a Thermo Evolution 300 recording spectrophotometer using $10 \mathrm{~mm}$ matched quartz cells and slit width $2 \mathrm{~nm}$. The $\mathrm{pH}-$ meter (HANNA HI 223) equipped with a radiometer combined glass electrode was used for $\mathrm{pH}$ measurements. The $\mathrm{pH}$ values in water-ethanol medium were corrected as described elsewhere [41].

2.2. Chemicals. All chemicals were of analytical reagent grade and distilled water was used for preparation of solutions. Freshly prepared stock solutions of $1 \times 10^{-4} \mathrm{~mol} \mathrm{~L}^{-1} \mathrm{DA}$ and AA were prepared by dissolving an accurately weighed amount of the reagent in distilled water (Figure 1). The ionic

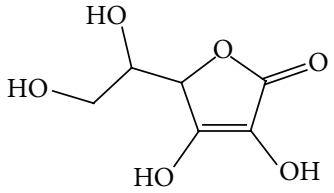

(a)

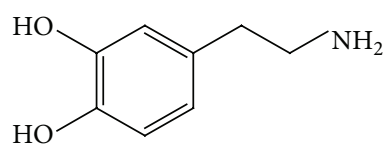

(b)

FIGURE 1: Structure of AA (a) and structure of DA (b).

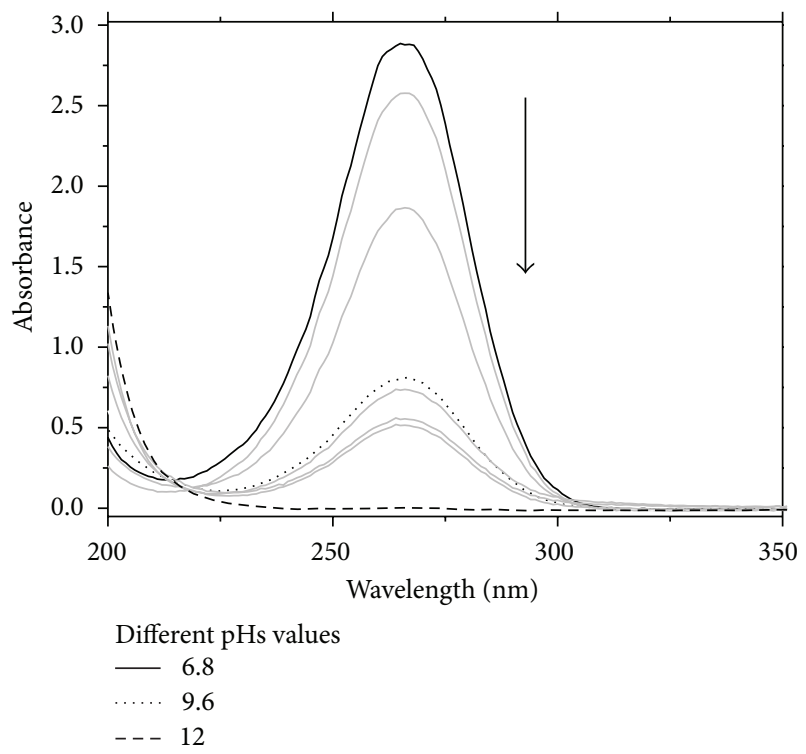

FIGURE 2: Effect of $\mathrm{pH}$ variation on the absorption spectra of AA, $[\mathrm{AA}]=1 \times 10^{-5} \mathrm{~mol} \mathrm{~L}^{-1}$.

strength of solutions was maintained at a constant value by using universal buffer. All measurements were made at $25^{\circ} \mathrm{C}$.

2.3. Standard Procedure. Aliquots of standard solutions of DA or AA were transferred into a $10-\mathrm{mL}$ calibrated flask, $2.5 \mathrm{~mL}$ of universal buffer was added to reach $\mathrm{pH} 9.2$, and the mixture was allowed to stand for $5 \mathrm{~min}$ at room temperature. The contents were then diluted to the mark and mixed well. The derivative absorbance at $D_{1}$ and $D_{2}$ max. was measured against water blank.

\section{Results and Discussion}

3.1. Effect of $p H$ on Dopamine and Ascorbic Acid. By using the universal buffer ( $\mathrm{pH}$; 5.5-11.5), one could see an increase in absorbance of DA to reach its maximum at $\mathrm{pH}$ 9.2. In contrary, there is a decrease in the absorbance of AA with increasing the $\mathrm{pH}$ of the solution, so the $\mathrm{pH} 9.2$ was selected for working condition as our main target was DA (see Figures 2 and 3). Although that DA has some absorbance in the visible region with increasing the $\mathrm{pH}$, this absorbance is very weak in comparison with the absorbance in the UV range, which is ten times higher in intensity than that in visible region that can provide higher sensitivity for the detection of DA in the UV region rather than the visible region. 


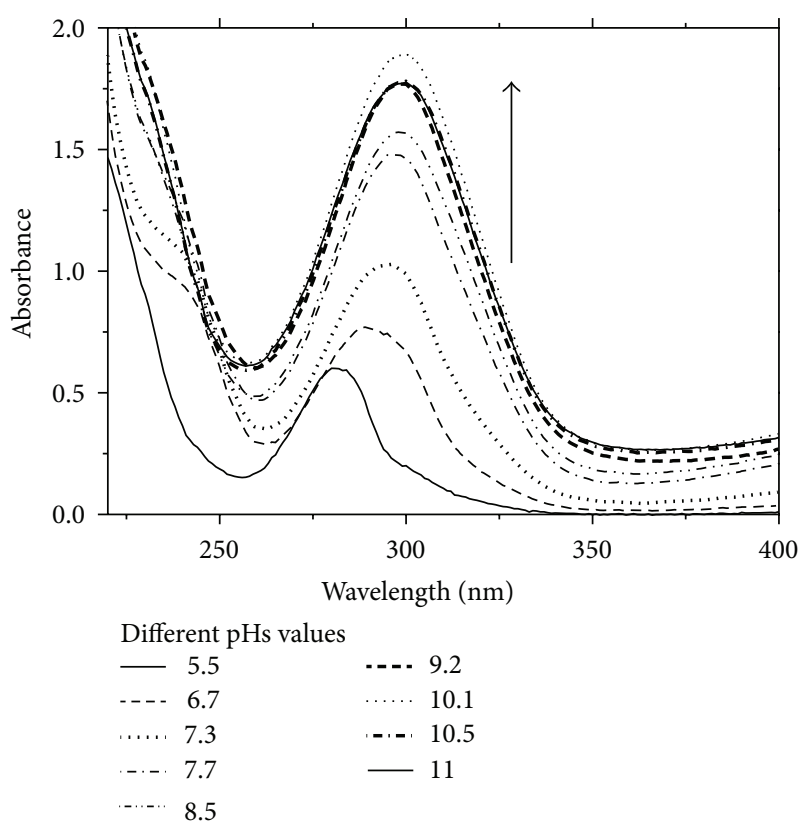

FIGURE 3: Effect of $\mathrm{pH}$ on the absorption spectra DA; [DA] $=2 \times$ $10^{-5} \mathrm{~mol} \mathrm{~L}^{-1}$.

3.2. Preliminary Studies. Figure 4 shows the absorption spectra of DA and AA in distilled water and it is observed that the spectra of these two compounds are completely overlapped and each compound interferes in the spectrophotometric determination of other one.

3.3. Optimum Instrumental Conditions. The main instrumental parameters that affect the shape of the derivative spectra are wavelength scanning speed and the wavelength increment over which the derivative is obtained $(\Delta \lambda)$. These parameters need to be optimized to give a well-resolved large peak, that is, to give good selectivity and large sensitivity in the determination process. Generally, the noise level decreases with an increase in $\Delta \lambda$, thus decreasing the fluctuations in the derivative spectrum. However, if the value of $\Delta \lambda$ is too large, the spectral resolution is very poor. Therefore, the optimum value of determined $\Delta \lambda$ was taken into account with the noise level, the resolution of the spectrum, and the sample concentration. Some values of $\Delta \lambda$ were tested and 2.0 was selected as the optimum. After careful study of lower and higher speeds the speed $(1200 \mathrm{~nm} / \mathrm{min})$ was selected.

3.4. First Derivative Spectrophotometry. From Figure 5, the obtained data show the first derivative absorption spectra of $1 \times 10^{-5} \mathrm{~mol} \mathrm{~L}^{-1}$ of DA and AA at $\mathrm{pH} 9.2$ after $5 \mathrm{~min}$. As Figure 4 shows large overlap of the spectral bands of the drugs between wavelengths $200.0-320.0 \mathrm{~nm}$, this prevents the simultaneous determination of these two compounds in the mixture from their zero-order spectra. However, the first derivative spectra allow the simultaneous determination of them. In DA for example, it has zero crossing points at wavelengths 258.8 and $286 \mathrm{~nm}$, where AA can be determined and DA can be determined at $265 \mathrm{~nm}$. Figure 5 shows the first

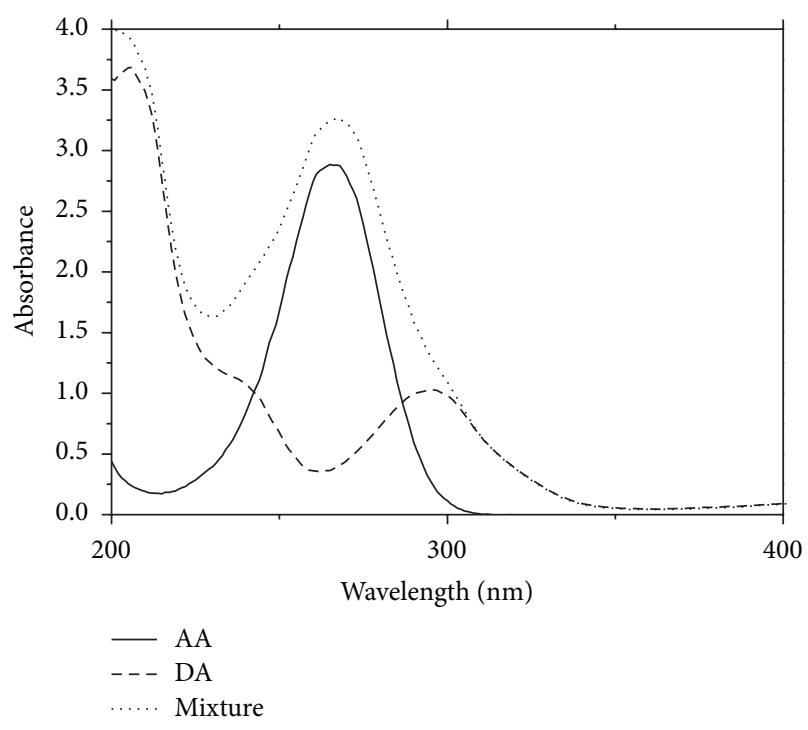

FIGURE 4: Zero-derivative spectra of $[\mathrm{DA}]=1 \times 10^{-5} \mathrm{~mol} \mathrm{~L}^{-1}$ and $[\mathrm{AA}]=1 \times 10^{-5} \mathrm{~mol} \mathrm{~L}^{-1}$, and a mixture of them contains the same concentration of both analytes.

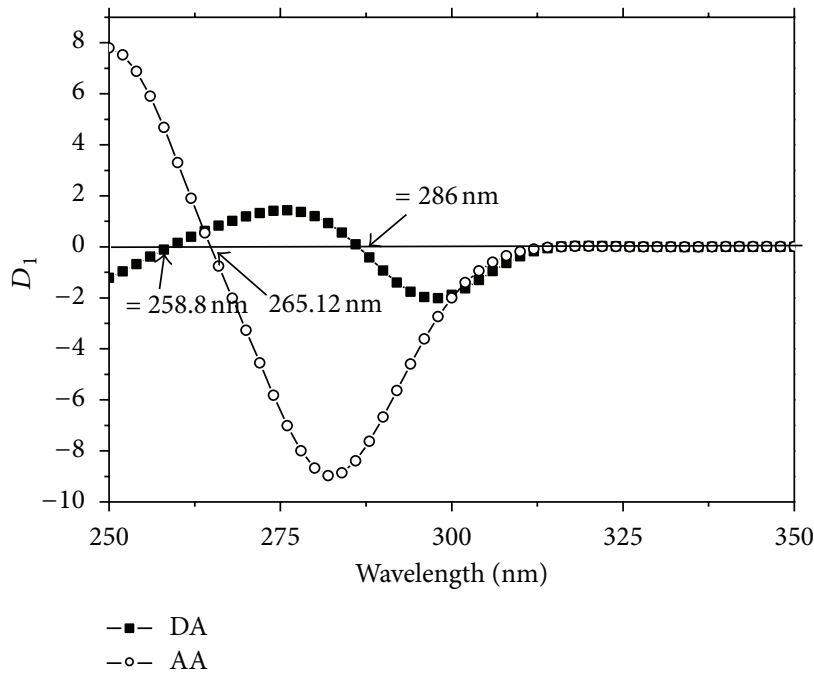

FIGURE 5: First derivative spectra of DA and AA; $[\mathrm{DA}]=[\mathrm{AA}]=$ $1 \times 10^{-5} \mathrm{~mol} \mathrm{~L}^{-1}$.

derivative spectra of DA with a wide range of concentration from 2 to $50 \mu \mathrm{M}$ (see Figure 6), while this range is from 2 to $30 \mu \mathrm{M}$ in $\mathrm{AA}$ as shown in Figure 7.

3.5. Second Derivative Spectrophotometry. Figures 8 and 9 show the second derivative absorption spectra of DA and AA at $\mathrm{pH} 9.2$ after $5 \mathrm{~min}$ with a range of concentrations $2-50 \mu \mathrm{M}$ and $2-2.4 \mu \mathrm{M}$, respectively.

3.6. Calibration Graphs and Statistical Treatment of the Results. The calibration graphs were constructed under the optimum conditions from the first and second derivative signals by measuring the highest of derivative value at 


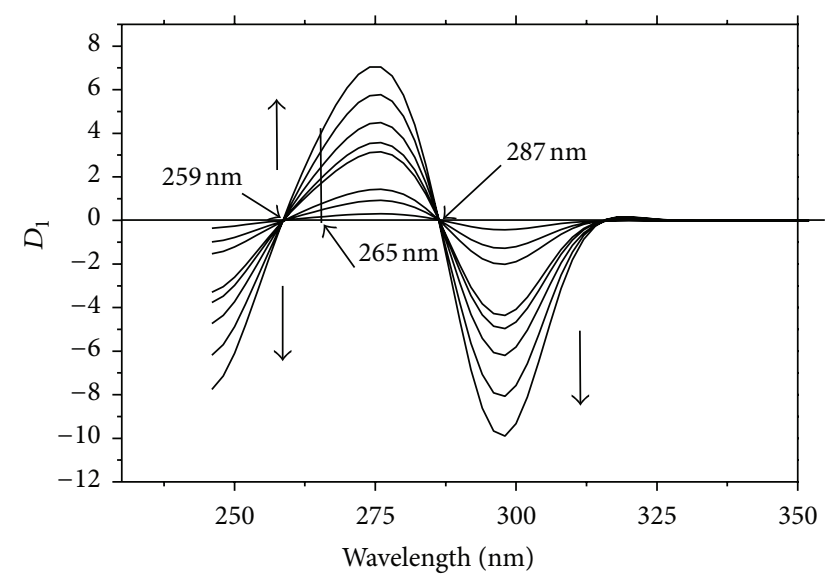

FIGURE 6: First derivative spectra of DA, (1) $2 \times 10^{-6}$, (2) $6 \times 10^{-6}$, (3) $1 \times 10^{-5}$, (4) $2 \times 10^{-5}$, (5) $2.4 \times 10^{-5}$, (6) $3 \times 10^{-5}$, (7) $4 \times 10^{-5}$, and (8) $5 \times 10^{-5} \mathrm{~mol} \mathrm{~L}^{-1}$.

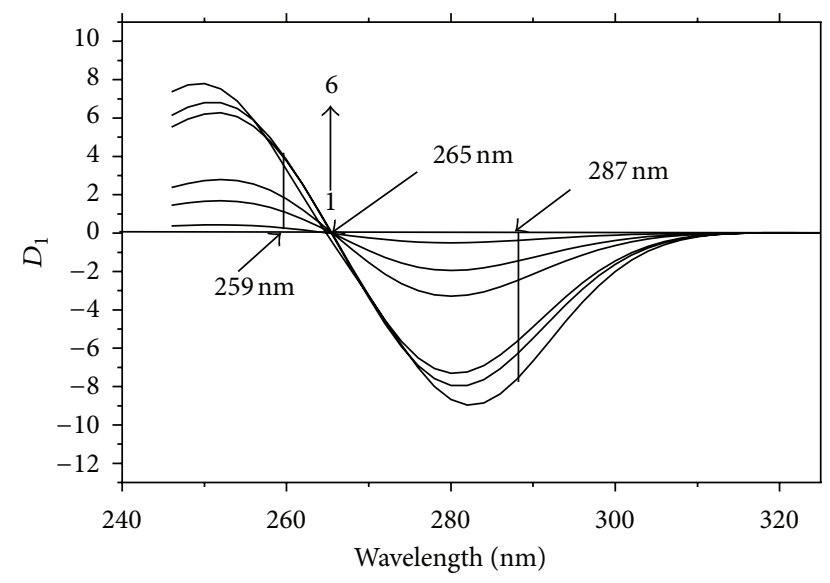

FIGURE 7: First derivative spectra of AA, (1) $2 \times 10^{-6}$, (2) $6 \times 10^{-6},(3)$ $1 \times 10^{-5}$, (4) $2 \times 10^{-5}$, (5) $2.4 \times 10^{-5}$, and (6) $3 \times 10^{-5} \mathrm{~mol} \mathrm{~L}^{-1}$.

different wavelengths for DA and AA. Table 1 shows the statistical analysis of the experimental data for both analytes. The regression equation was calculated from the calibration graph, along with standard deviations of the slope and the intercept of the ordinate; the high value of the correlation coefficient indicates the good linearity of the calibration graph, and we check the better derivative equation by analysis of known mixture between DA and AA. In Table $1, D_{1}$ of $\mathrm{DA}$ and AA are measured at $265 \mathrm{~nm}$ and 259 and $287 \mathrm{~nm}$, respectively, while the $D_{2}$ of DA and AA are measured at 251 and $281 \mathrm{~nm}$ and 275 and $297 \mathrm{~nm}$, respectively.

The precision was ascertained by carrying out four replicate determinations of synthetic mixtures of DA and AA. The relative standard deviations for four replicate determinations of a mixture containing $2 \times 10^{-5} \mathrm{~mol} \mathrm{~L}^{-1}$ of DA and AA indicate reasonable repeatability of the proposed method; these results are given in Table 1 . The accuracy was tested by the determination of mixture containing different concentrations of DA and AA. The recovery values were calculated for DA and $\mathrm{AA}$ and depending on these values the best equations

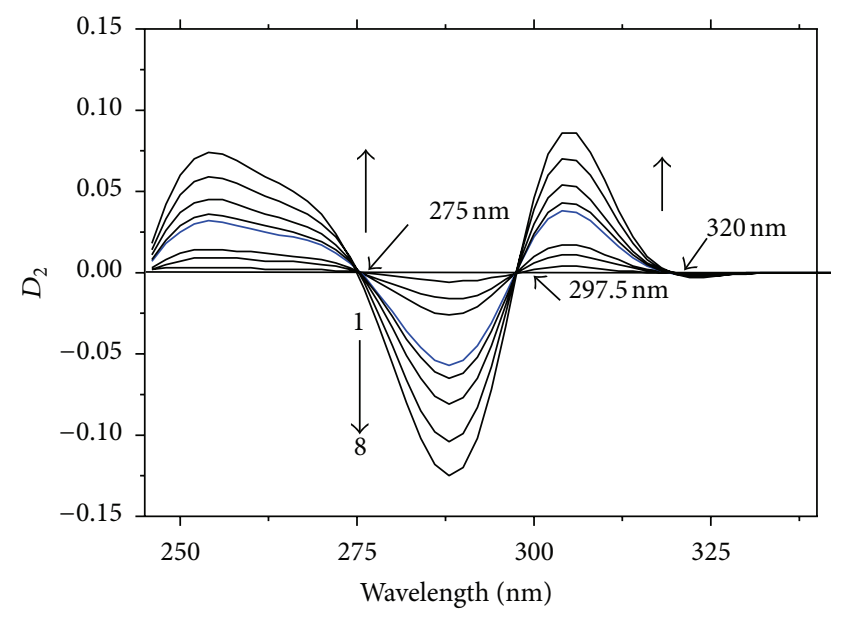

FIGURE 8: Second derivative spectra of DA, (1) $2 \times 10^{-6}$, (2) $6 \times 10^{-6}$, (3) $1 \times 10^{-5}$, (4) $2 \times 10^{-5}$, (5) $2.4 \times 10^{-5}$, (6) $3 \times 10^{-5}$, (7) $4 \times 10^{-5}$, and (8) $5 \times 10^{-5} \mathrm{~mol} \mathrm{~L}^{-1}$.

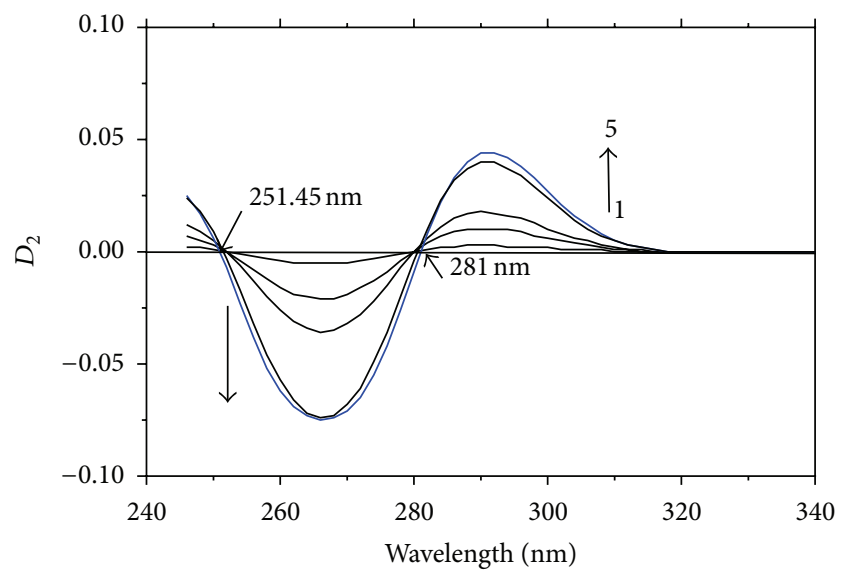

FIGURE 9: Second derivative spectra of AA, (1) $2 \times 10^{-6}$, (2) $6 \times 10^{-6}$, (3) $1 \times 10^{-5}$, (4) $2 \times 10^{-5}$, and (5) $2.4 \times 10^{-5} \mathrm{~mol} \mathrm{~L}^{-1}$.

were selected for measuring synthetic mixtures of DA and AA; these results are given in Table 2 .

3.7. Interferences. Some common interferences such as lactose (700 times), starch (250 times), glucose (950 times), sucrose (700 times), and fructose (950 times), which are usually present in preparation of tablets and capsules, show no influence on the determination of DA and AA by proposed method at low levels.

3.8. Application. Although most of the previous works were done to determine both analytes without informing about specific drug that contains the two analytes, we have tried here in this paper as was reported before in [30-38] to apply our method to drugs with adding the other analyte and in addition determine these analytes in the human urine. These methods are successful to determine both reagents with good standard deviations in real samples (human urine), which was treated like in [54], and in synthetic mixtures using 
TABLE 1: Statistical analysis of the determination of dopamine and ascorbic acid in mixtures by first and second derivative spectrophotometry.

\begin{tabular}{lcccccccc}
\hline Compound & $\begin{array}{c}\text { Order of } \\
\text { derivative }\end{array}$ & $\begin{array}{c}\text { Wavelength } \\
(\mathrm{nm})\end{array}$ & $\begin{array}{c}\text { Linearity range } \\
\left(\mathrm{mg} \mathrm{L}^{-1}\right)\end{array}$ & Intercept & Slope & $\begin{array}{c}\text { Regression } \\
\text { coefficient }^{2}\end{array}$ & $\begin{array}{c}\text { RSD } \\
(\%)\end{array}$ & $\begin{array}{c}\text { Recovery } \\
(\%)^{\mathrm{a}}\end{array}$ \\
\hline \multirow{2}{*}{$\mathrm{DA}$} & $D_{1}$ & 265.12 & $0.375-9.45$ & -0.016 & 78210.57 & 0.998 & 0.60 & 110.0 \\
& & 251 & $0.375-9.45$ & $1.00 E-4$ & 1274.71 & 0.999 & 2.0 & 100.0 \\
& $D_{2}$ & 281 & $0.375-9.45$ & $-8.03 E-4$ & -1323.47 & 0.998 & 2.4 & 100.0 \\
& & 259 & $0.352-3.52$ & -0.233 & 233212.29 & 0.999 & 1.22 & 100.0 \\
& $D_{1}$ & 287 & $0.352-5.28$ & 0.037 & -282224.66 & 0.995 & 1.12 & 110.0 \\
$\mathrm{AA}$ & $D_{2}$ & 275 & $0.352-5.28$ & $6.12 E-4$ & -2062.77 & 0.997 & 2.2 & 101.0 \\
\hline
\end{tabular}

${ }^{\mathrm{a}}$ Sample: $3.78 \mathrm{mg} \mathrm{L}^{-1}$ of DA and $3.52 \mathrm{mg} \mathrm{L}^{-1}$ of AA.

TABLE 2: Determination of dopamine and ascorbic acid in synthetic mixtures and real samples by first and second derivative spectrophotometry.

\begin{tabular}{lccccc}
\hline \multirow{2}{*}{ Sample number } & \multicolumn{5}{c}{ Recovery (\%) } \\
& $D_{2}{ }^{251}$ & $D_{2}{ }^{281}$ & $D_{1}{ }^{259}$ & $D_{2}{ }^{275}$ & $D_{2}{ }^{297}$ \\
\hline 1 & 100 & 100 & 100 & 104 & 102 \\
2 & 98 & 99 & 100 & 98 & 100 \\
3 & 99 & 100 & 100 & 101 & 101 \\
4 & 99 & 100 & - & - & - \\
5 & - & - & 100 & 98 & 99 \\
Urine 1 & 100 & 99 & 99 & 98 & 98 \\
Urine 2 & 99 & 99 & 99 & 100 & 99 \\
\hline
\end{tabular}

Sample 1: $1.89 \mathrm{mg} \mathrm{L}^{-1}$ of DA and $3.52 \mathrm{mg} \mathrm{L}^{-1}$ of AA, Sample 2: $3.78 \mathrm{mg} \mathrm{L}^{-1}$ of DA and $1.76 \mathrm{mg} \mathrm{L}^{-1}$ of AA, Sample 3: $1.89 \mathrm{mg} \mathrm{L}^{-1}$ of DA and $1.76 \mathrm{mg} \mathrm{L}^{-1}$ of AA, Sample 4: injection content $200 \mathrm{mg} / 5 \mathrm{~mL}$, Sample 5: tablet content $100 \mathrm{mg}$. Average of three determinations based on the drug label. Urine 1: $2.0 \mathrm{mg} \mathrm{L}^{-1}$ of DA and $2.16 \mathrm{mg} \mathrm{L}^{-1}$ of AA were added; Urine $2: 1.95 \mathrm{mg} \mathrm{L}^{-1}$ of $\mathrm{DA}$ and $2.06 \mathrm{mg} \mathrm{L}^{-1}$ of AA were added.

the usual procedure as is described above. The proposed method has been successfully applied to the determination of DA and AA in synthetic mixtures containing different ratios of both drugs and in some pharmaceutical samples (DA injection and AA tablet) with the main interfering substances to AA and DA. The results are given in Table 2 using the best wavelengths for determining both analytes from Table 1 . In Table 2, one can observe that there is no significant difference between the results obtained by the proposed method and the reported values.

\section{Conclusions}

Although derivative methods are quite old but no one before to our best of knowledge has used it to determine these two reagents. The proposed methods are simple (no need for solvent extraction or chemical reaction), rapid (as it only requires measurements of $D_{1}$ and $D_{2}$ values at different wavelengths), direct (as it estimates each drug independently of the other), and friendly to the environment (no need to use neither synthesized materials nor nanoparticles which do not have specific precaution to the environment). This paper demonstrates the potential of first and second derivative spectrophotometry methods as analytical techniques and their usefulness to obtain accurate, rapid, simple, and simultaneous quantization of DA and AA in pharmaceutical preparation and urine samples. In comparison with previous techniques, this method may be considered as a green tool for determination DA and $\mathrm{AA}$ in aqueous medium. It can also be seen from Table 2 that the second derivative in general is more favorable than the first derivative for the simultaneous determination of dopamine and ascorbic acid.

\section{References}

[1] Y.-F. Tsai, H.-W. Tsai, and M.-Y. Tai, "Comparison of brain dopamine depletion induced by low-dose 1-methyl-4-phenyl1,2,3,6-tetrahydropyridine (MPTP) in young and aged rats," Neuroscience Research, vol. 20, no. 1, pp. 27-33, 1994.

[2] United States Pharmacopoeia XXIII, National Formulary XVIII, United States Pharmacopoeial Convention, Rockville, Md, USA, 1995.

[3] I. A. Biryuk, V. V. Petrenko, and B. P. Zorya, "Spectrophotometric determination of dopamine by reaction with ninhydrine," Farmatsevticheskii Zhurnal, vol. 2, p. 57, 1992.

[4] K. R. Dutt, T. N. Prasad, M. S. Murthy, and E. V. Rao, "Spectrophotometric determination of dopamine hydrochloride using MBTH and CE(IV)," Indian Drugs, vol. 29, no. 4, pp. 181-183, 1992.

[5] C. Martinez-Lozano, T. Perez-Ruiz, V. Tomas, and O. Val, "Determination of epinephrine, norepinephrine, dopamine and L-dopa in pharmaceuticals by a photokinetic method," Analyst, vol. 116, no. 8, pp. 857-859, 1991.

[6] M. E. el-Kommos, F. A. Mohamed, and A. S. Khedr, "Spectrophotometric determination of some catecholamine drugs using metaperiodate," Journal of the Association of Official Analytical Chemists, vol. 73, no. 4, pp. 516-520, 1990.

[7] G. R. Rao, A. B. Avadhanulu, and R. Giridhar, "Spectrophotometric determination of dopamine hydrochloride, dobutamine hydrochloride in their dosage forms," Indian Drugs, vol. 25, no. 9, pp. 382-384, 1988.

[8] M. E. El-Kommos, "Spectrophotometric assay of dopamine hydrochloride injection using thiosemicarbazide," Journal de Pharmacie de Belgique, vol. 42, no. 6, pp. 371-376, 1987.

[9] R. T. Sane, P. M. Deshpande, C. L. Sawant, S. M. Dolas, V. G. Nayak, and S. S. Zarapkar, "Simple spectrophotometric 
method for the determination of dopamine hydrochloride," Indian Drugs, vol. 24, p. 199, 1987.

[10] C. S. Sastry, V. G. Das, and K. E. Rao, "Spectrophotometric methods for the determination of o-dihydroxybenzene derivatives," Analyst, vol. 110, no. 4, pp. 395-398, 1985.

[11] F. Ortega and E. Domínguez, "Selective catalytic detection of dopamine," Journal of Pharmaceutical and Biomedical Analysis, vol. 14, no. 8-10, pp. 1157-1162, 1996.

[12] J. J. B. Nevado, J. M. L. Gallego, and P. B. Laguna, "Flowinjection spectrophotometric determination of adrenaline and dopamine with sodium hydroxide," Journal of Pharmaceutical and Biomedical Analysis, vol. 14, no. 5, pp. 571-577, 1996.

[13] J. J. Berzas Nevado, J. M. Lemus Gallego, and P. Buitrago Laguna, "Spectrophotometric determination of dopamine and methyldopa with metaperiodate by flow injection analysis," Fresenius' Journal of Analytical Chemistry, vol. 353, no. 2, pp. 221-223, 1995.

[14] J. J. Berzas, J. M. Lemus, and P. Buitrago, "Stopped-flow spectrophotometric determination of dopamine and methyldopa with sodium hydroxide," Analytical Letters, vol. 30, no. 6, pp. 1109-1120, 1997.

[15] D. Djozan and M. A. Farajzadeh, "The use of fluorescamine (Fluram) in fluorimetric trace analysis of primary amines of pharmaceutical and biological interest," Journal of Pharmaceutical and Biomedical Analysis, vol. 10, no. 10-12, pp. 1063-1067, 1992.

[16] H. Y. Wang, Y. Sun, and B. Tang, "Study on fluorescence property of dopamine and determination of dopamine by fluorimetry," Talanta, vol. 57, no. 5, pp. 899-907, 2002.

[17] H. Y. Wang, Q. S. Hui, L. X. Xu, J. G. Jiang, and Y. Sun, "Fluorimetric determination of dopamine in pharmaceutical products and urine using ethylene diamine as the fluorigenic reagent," Analytica Chimica Acta, vol. 497, no. 1-2, pp. 93-99, 2003.

[18] H. Nohta, T. Yukizawa, Y. Ohkura, M. Yoshimura, J. Ishida, and M. Yamaguchi, "Aromatic glycinonitriles and methylamines as pre-column fluorescence derivatization reagents for catecholamines," Analytica Chimica Acta, vol. 344, no. 3, pp. 233240, 1997.

[19] K. Fujino, T. Yoshitake, J. Kehr, H. Nohta, and M. Yamaguchi, "Simultaneous determination of 5-hydroxyindoles and catechols by high-performance liquid chromatography with fluorescence detection following derivatization with benzylamine and 1,2-diphenylethylenediamine," Journal of Chromatography A, vol. 1012, no. 2, pp. 169-177, 2003.

[20] X. Wu, C. Tong, B. Su, F. Huang, and J. Yang, "Determination of dopamine by fluorimetry," Fenxi Huaxue, vol. 27, no. 9, pp. 1069-1071, 1999.

[21] X. Zhu, P. N. Shaw, and D. A. Barrett, "Catecholamines derivatized with 4-fluoro-7-nitro-2,1,3-benzoxadiazole: characterization of chemical structure and fluorescence properties," Analytica Chimica Acta, vol. 478, no. 2, pp. 259-269, 2003.

[22] N. T. Deftereos, A. C. Calokerinos, and C. E. Efstathiou, "Flow injection chemiluminometric determination of epinephrine, norepinephrine, dopamine and L-dopa," Analyst, vol. 118, no. 6, pp. 627-632, 1993.

[23] T. Peng, L. Yang, H. Yang, G. Wang, and B. Shen, "Selective accumulation and electrochemical behavior of neurotransmitter dopamine at glassy carbon electrode modified by sodium montmorillonite," Fenxi Huaxue, vol. 25, no. 1, pp. 5-9, 1997.

[24] W. Peng and E. Wang, "Preparation and characterization of a multi-cylinder microelectrode coupled with a conventional glassy carbon electrode and its application to the detection of dopamine," Analytica Chimica Acta, vol. 281, no. 3, pp. 663-671, 1993.

[25] O. Niwa, M. Morita, and H. Tabei, "Highly sensitive and selective voltammetric detection of dopamine with vertically separated interdigitated array electrodes," Electroanalysis, vol. 3, no. 3, pp. 163-168, 1991.

[26] E. Bishop and W. Hussein, "Anodic voltammetry of dopamine, noradrenaline and related compounds at rotating disc electrodes of platinum and gold," Analyst, vol. 109, no. 5, pp. 627632, 1984.

[27] A. G. Fogg, A. M. Summan, and M. A. Fernandez-Arciniega, "Flow injection amperometric determination of ascorbic acid and dopamine at a sessile mercury drop electrode without deoxygenation," Analyst, vol. 110, no. 4, pp. 341-343, 1985.

[28] J. L. Ponchon, R. Cespuglio, F. Gonon, M. Jouvet, and J. Francois Pujol, "Normal pulse polarography with carbon fiber electrodes for in vitro and in vivo determination of catecholamines," Analytical Chemistrty, vol. 51, no. 9, pp. 1483-1486, 1979.

[29] Y. Wu, R. Fan, and J. Di, "Electrochemical study of electron transfer between dopamine and ferrocene at liquid/liquid interface," Fenxi Huaxue, vol. 24, no. 8, pp. 873-876, 1996.

[30] S. Yixin and S. Fu Wang, "Simultaneous determination of dopamine and ascorbic acid at a triazole self-assembled monolayer-modified gold electrode," Microchimica Acta, vol. 154, no. 1-2, pp. 115-121, 2006.

[31] A. I. Gopalan, K.-P. Lee, K. M. Manesh, P. Santhosh, J. H. Kim, and J. S. Kang, "Electrochemical determination of dopamine and ascorbic acid at a novel gold nanoparticles distributed poly(4-aminothiophenol) modified electrode," Talanta, vol. 71, no. 4, pp. 1774-1781, 2007.

[32] J. B. Raoof, A. Kiani, R. Ojani, R. Valiollahi, and S. RashidNadimi, "Simultaneous voltammetric determination of ascorbic acid and dopamine at the surface of electrodes modified with self-assembled gold nanoparticle films," Journal of Solid State Electrochemistry, vol. 14, no. 7, pp. 1171-1176, 2010.

[33] D. Ragupathy, A. I. Gopalan, and K.-P. Lee, "Electrocatalytic oxidation and determination of ascorbic acid in the presence of dopamine at multiwalled carbon nanotube-silica network-gold nanoparticles based nanohybrid modified electrode," Sensors and Actuators B, vol. 143, no. 2, pp. 696-703, 2010.

[34] X. Cao, L. Luo, Y. Ding, X. Zou, and R. Bian, "Electrochemical methods for simultaneous determination of dopamine and ascorbic acid using cetylpyridine bromide/chitosan composite film-modified glassy carbon electrode," Sensors and Actuators $B$, vol. 129, no. 2, pp. 941-946, 2008.

[35] L.-Q. Luo, Q.-X. Li, Y.-P. Ding, Y. Zhang, and X. Shen, "Docosyltrimethylammonium chloride modified glassy carbon electrode for simultaneous determination of dopamine and ascorbic acid," Journal of Solid State Electrochemistry, vol. 14, no. 7, pp. 1311-1316, 2010.

[36] M. Reza Hormozi Nezhad, J. Tashkhourian, J. Khodaveisi, and M. Reza Khoshi, "Simultaneous colorimetric determination of dopamine and ascorbic acid based on the surface plasmon resonance band of colloidal silver nanoparticles using artificial neural networks," Analytical Methods, vol. 2, no. 9, pp. 12631269, 2010.

[37] D. R. Shankaran, K. Iimura, and T. Kato, "Simultaneous determination of ascorbic acid and dopamine at a sol-gel composite electrode," Sensors and Actuators B, vol. 94, no. 1, pp. 73-80, 2003. 
[38] R. M. Wightman and D. L. Robinson, "Transient changes in mesolimbic dopamine and their association with 'reward"' Journal of Neurochemistry, vol. 82, no. 4, pp. 721-735, 2002.

[39] S. Yuan, W. H. Chen, and S. S. Hu, "Fabrication of $\mathrm{TiO}_{2}$ nanoparticles/surfactant polymer complex film on glassy carbon electrode and its application to sensing trace dopamine," Materials Science and Engineering C, vol. 25, no. 4, pp. 479-485, 2005.

[40] C. R. Raj, K. Tokuda, and T. Ohsaka, "Electroanalytical applications of cationic self-assembled monolayers: square-wave voltammetric determination of dopamine and ascorbate," Bioelectrochemistry, vol. 53, no. 2, pp. 183-191, 2001.

[41] V. J. Hammond and W. C. Price, "A new system for the elimination of scattered light effects in spectrophotometers," Journal of the Optical Society of America, vol. 43, no. 10, p. 924, 1953.

[42] J. D. Morrison, "Studies of ionization efficiency. Part III. The detection and interpretation of fine structure," Journal of Chemical Physics, vol. 21, p. 1767, 1953.

[43] A. T. Giese and C. S. French, "The analysis of overlapping spectral absorption bands by derivative spectrophotometry," Applied Spectroscopy, vol. 9, no. 2, pp. 78-101, 1955.

[44] M. Yamaguchi and M. Yoshimura, "Simultaneous determination of urinary catecholamines and 5-hydroxyindoleamines by high-performance liquid chromatography with fluorescence detection," Analyst, vol. 123, pp. 307-311, 1998.

[45] W. Snelleman, T. C. Rains, K. W. Yee, H. D. Cook, and O. Menis, "Flame emissionspectrometry with repetitive optical scanning in the derivative mode," Analytical Chemistry, vol. 42, no. 3, pp. 394-398, 1970

[46] W. K. Fowler, D. O. Knapp, and J. D. Winefordner, "Double modulation atomic fluorescence flame spectrometry," Analytical Chemistry, vol. 46, no. 4, pp. 601-602, 1974.

[47] T. C. O'Haver, "Modulation and derivative techniques in luminescence spectroscopy: approaches to increased analytical selectivity," in Modern Fluorescence Spectroscopy, E. L. Wehry, Ed., vol. 1, p. 65, Plenum Press, New York, NY, USA, 1976.

[48] T. C. O'Haver, "Derivative spectroscopy and its applications in analysis," Analytical Proceedings, vol. 19, pp. 22-46, 1982.

[49] H. Ishii and K. Z. Satoch, "Determination of micro amounts of samarium and europium by analogue derivative spectrophotometry," Analytical Chemistry, vol. 312, no. 2, pp. 114-120, 1982.

[50] P. Levillain and D. Fompeyide, "Spectrophotométrie dérivée: intérêt, limites et applications," Analysis, vol. 14, pp. 1-20, 1986.

[51] T. C. O’Haver and G. L. Green, "Numerical error analysis of derivative spectrometry for the quantitative analysis of mixtures," Analytical Chemistry, vol. 48, no. 2, pp. 312-318, 1976.

[52] J. Medinilla, F. Ales, and F. G. Sanchez, "Spectrophotometric and second-derivative spectrophotometric determination of mercury in organomercurials by means of benzyl 2-pyridyl ketone 2-quinolylhydrazone," Talanta, vol. 33, no. 4, pp. 329$334,1986$.

[53] F. G. Sanchez, M. H. Lopez, and J. C. M. Gomez, "A graphical derivative approach to the photometric determination of lutetium and praseodymium in mixtures," Talanta, vol. 34, no. 7, pp. 639-644, 1987.

[54] Z. D. Peterson, D. C. Collins, C. R. Bowerbank, M. L. Lee, and S. W. Graves, "Determination of catecholamines and metanephrines in urine by capillary electrophoresiselectrospray ionization-time-of-flight mass spectrometry," Journal of Chromatography B, vol. 776, no. 2, pp. 221-229, 2002. 

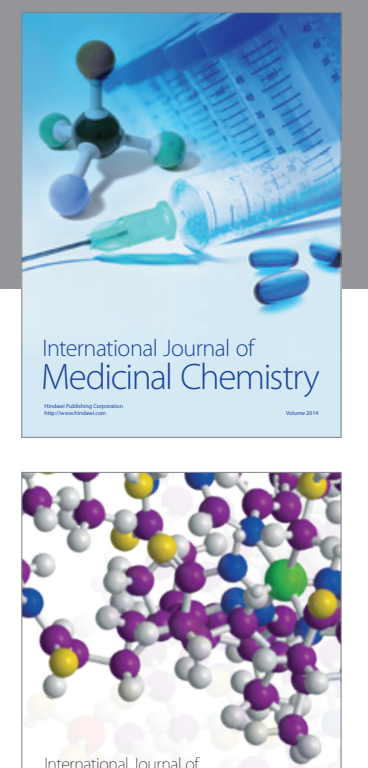

\section{Carbohydrate} Chemistry

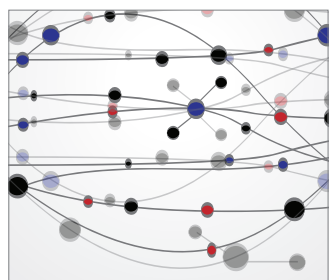

The Scientific World Journal
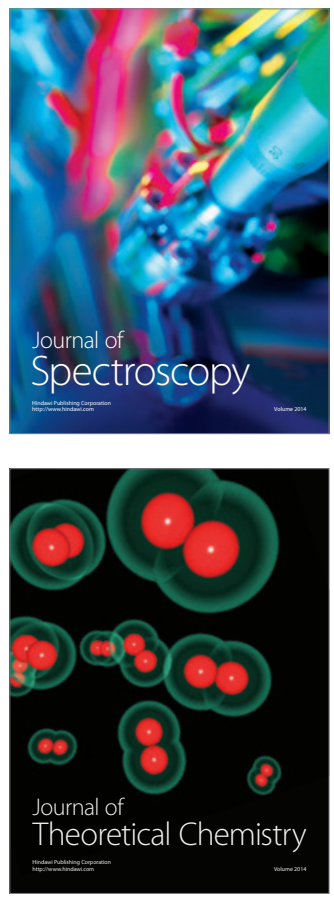
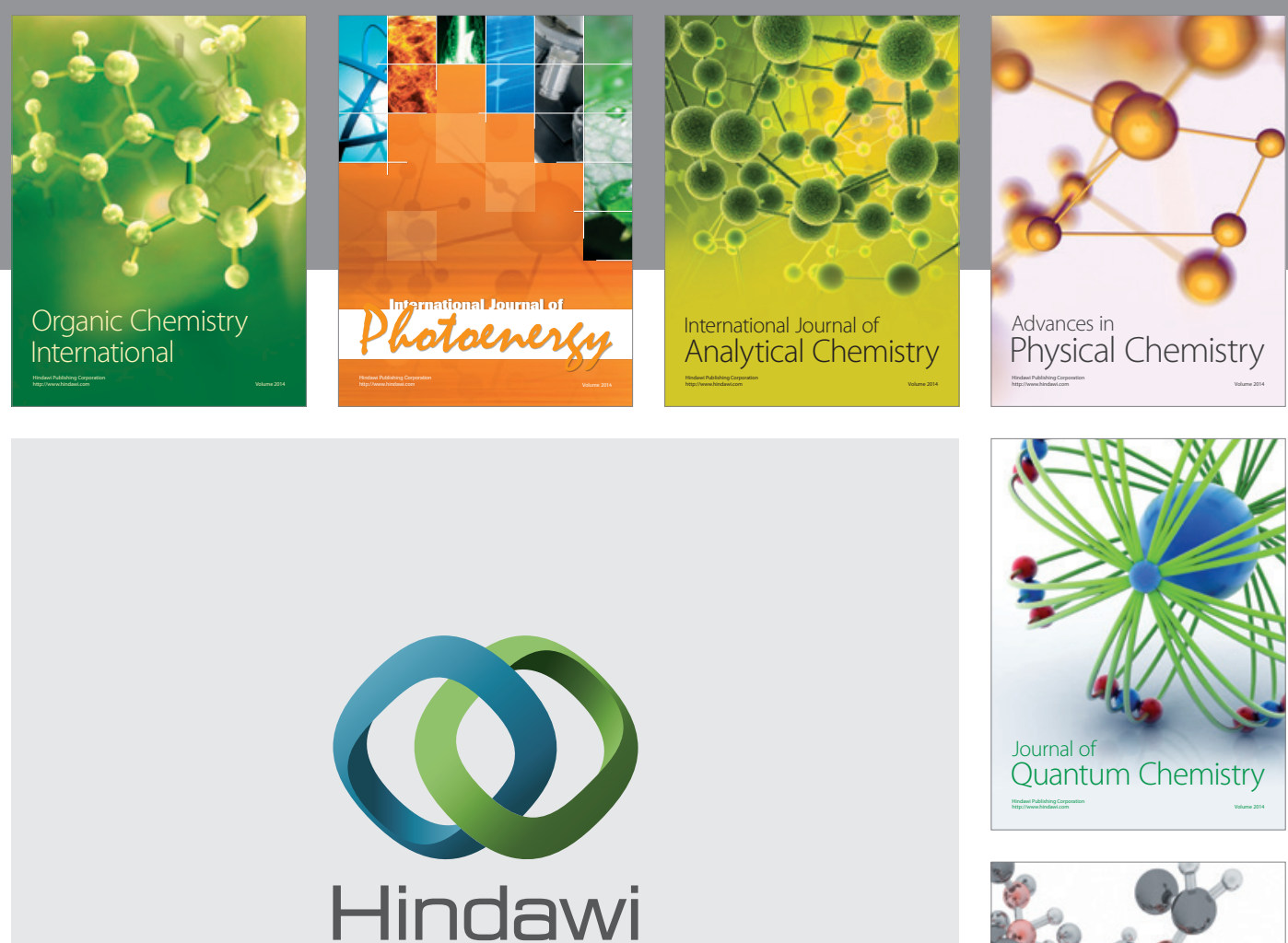

Submit your manuscripts at

http://www.hindawi.com

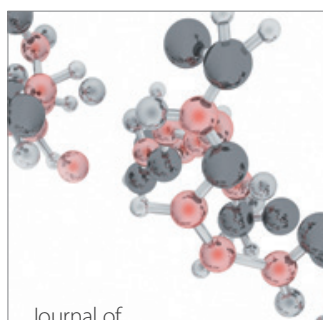

Analytical Methods

in Chemistry

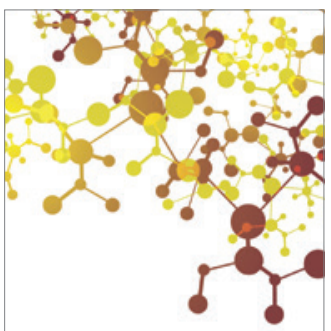

Journal of

Applied Chemistry

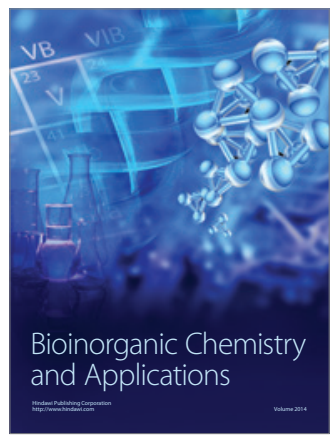

Inorganic Chemistry
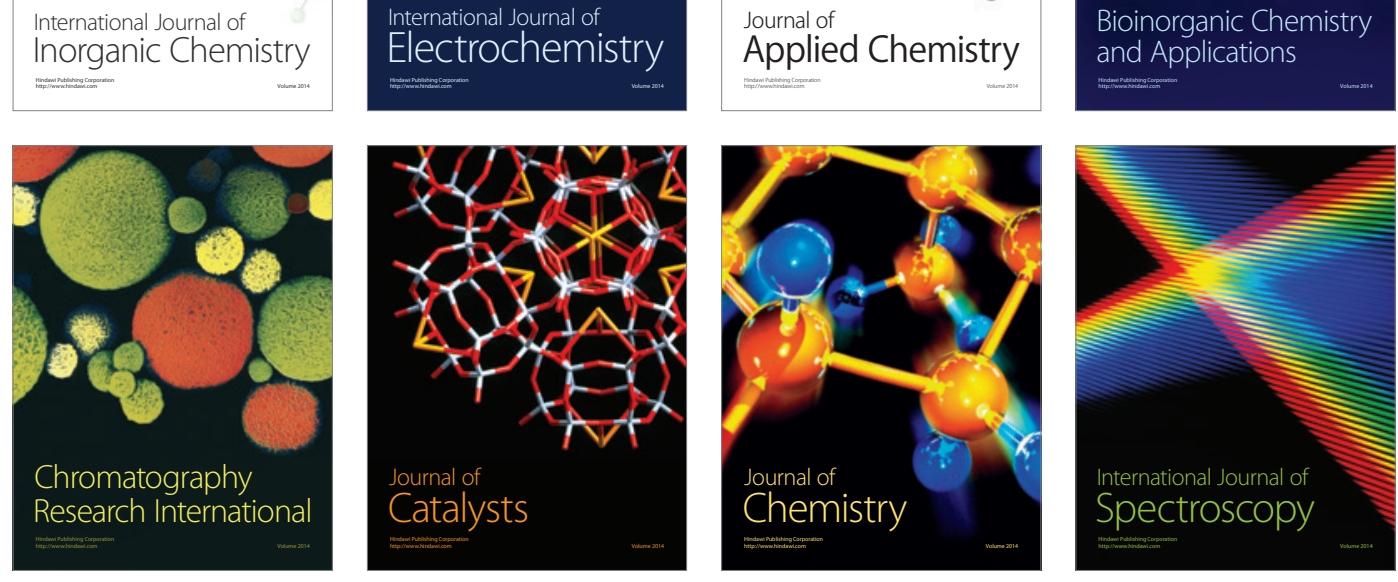